\title{
Genetic variant of the renin-angiotensin system and prevalence of type 2 diabetes mellitus: a modest but significant effect of aldosterone synthase
}

\author{
Mai Ichikawa $\cdot$ Tadashi Konoshita $\cdot$ Takahiro Nakaya $\cdot$ Katsushi Yamamoto $\cdot$ \\ Mika Yamada · Satsuki Sato $\cdot$ Michiko Imagawa $\cdot$ Yasukazu Makino $\cdot$ Miki Fujii • \\ Yasuo Zenimaru $\cdot$ Kenichiro Arakawa $\cdot$ Jinya Suzuki $\cdot$ Tamotsu Ishizuka $\cdot$ Hiroyuki Nakamura
}

Received: 14 December 2013/Accepted: 24 January 2014/Published online: 19 February 2014

(C) The Author(s) 2014. This article is published with open access at Springerlink.com

\begin{abstract}
Recent genome-wide association studies have identified multiple variants that confer risk of type 2 diabetes mellitus (DM). However, established associations explain only a part of the heritability. Thus, even at the genome-wide association studies era, candidate gene approach should be still useful. Recent interventional studies against the renin-angiotensin system (RAS) showed reduction in new onset of DM, implying the system is involved in the onset. We substantiated the hypothesis that genetic variants of RAS have significant association with prevalence of DM. We enrolled to the study consecutive 782 subjects who had consulted our hospitals for mainly lifestyle related diseases. They consisted of 282 (36.1\%) diabetes cases. Genotypes were assayed with genomic DNA for conventional four genes of the RAS, i.e., angiotensin converting enzyme (ACE) insertion/deletion variant, angiotensinogen (AGT) M235T variant, angiotensin II type I receptor (AT1) A1166C variant, and aldosterone synthase (CYP11B2) C-344T variant. Association between the genetic variants of the RAS and prevalence of type 2 DM
\end{abstract}

Communicated by Antonio Secchi.

For the Genomic Disease Outcome Consortium (G-DOC) Study Investigators.

M. Ichikawa - T. Konoshita ( $)$ - T. Nakaya - K. Yamamoto ·

M. Yamada - S. Sato · M. Imagawa - Y. Makino · M. Fujii ·

Y. Zenimaru · K. Arakawa · J. Suzuki · T. Ishizuka

Third Department of Internal Medicine, Faculty of Medical

Sciences, University of Fukui, 23-3, Matsuokashimoaizuki,

Eiheiji, Fukui 910-1193, Japan

e-mail: konosita@u-fukui.ac.jp

H. Nakamura

Department of Environmental and Preventive Medicine,

Kanazawa University Graduate School of Medical Science,

Kanazawa, Japan was tested. A significant association of DM and CYP11B2 genotype was obtained. There was no significant association between DM and ACE, AGT and AT1 variants. A multivariate logistic regression showed that age, gender, and CYP11B2 genotype were independent factors for association to diabetes, the DM risk of CC/CT to TT being 1.40 (95\% CI 1.04-1.90, $p=0.029$ ). Thus, it is concluded that a genetic variant of the RAS should have a modest but significant impact on the onset of type 2 diabetes mellitus.

Keywords Renin-angiotensin system · Gene polymorphism - Diabetes · Aldosterone $\cdot$ CYP11B2

\section{Introduction}

In contrast to the standard candidate gene approach method, genome-wide association studies (GWAS), as one ultimate style of reverse genetics method, have been expected to identify considerable part of risk alleles and applied to diabetes (DM). Thus, recently, the GWAS have identified multiple loci containing variants that confer risk of type 2 diabetes mellitus [1-3]. However, established associations to common and rare variants explain only a part of the heritability of type $2 \mathrm{DM}$. This limit of GWAS is thought to be attributed to the so-called genome-wide significance level $\left(p<5 \times 10^{-8}\right)$. Thus, even at the GWAS era, candidate gene approach should be still useful to find new important responsible genes of poly genic disorders. The renin-angiotensin system (RAS) plays major roles in blood pressure regulation and electrolyte metabolism [4]; on the other hand, the over-activation of the RAS is thought to play pivotal roles in the pathophysiology of cardiovascular [5], renal [6], and metabolic conditions [7]. A sufficient number of clinical trials provided a firm effectiveness of blockade on the RAS 
against cardiovascular and renal conditions [8-10]. At the same time, the blockade showed the reduction in new onset of type 2 DM [11-13]. The genetic variants are also associated divers clinical aspects [14-16]. These observations are strongly implying that the RAS might be involved in the onset of DM itself.

Thus, in this study, we substantiated the hypothesis that genetic variants of the RAS have significant association with prevalence of type $2 \mathrm{DM}$.

\section{Methods}

\section{Subjects and genotyping}

We enrolled to the study consecutive 782 subjects who had consulted our hospitals for mainly lifestyle related diseases (hypertension, diabetes, dyslipidemia, and chronic kidney disease) with no special selection between June 2000 and July 2013. The study was undertaken in accordance with the 1975 Declaration of Helsinki Principles revised in 2008. The study was approved by the ethics committee of Fukui University (No. 13-1, 14-2), and written informed consent for participation was obtained from all individuals. Diabetes was diagnosed according to the criteria of the World Health Organization. Subjects with age $<20$ years old, type 1 diabetes, gestational diabetes, secondary diabetes, severe organ failure, and acute phase disorders were excluded. At the blood sampling, all subjects had been under the condition without any anti-hypertensive or anti-dyslipidemic agent at least 1 week. Diabetic subjects continued to receive their usual care for diabetes. The subjects consisted of $282(36.1 \%)$ diabetes cases and 365 (46.7 \%) male cases. Mean age, body mass index (BMI), blood glucose level, glycosylated hemoglobin A1c, low-density lipoprotein, and estimated glomerular filtration rate (eGFR) were $63.0 \pm 13.9$ years, $23.9 \pm 3.9$, $119.7 \pm 42.7 \mathrm{mg} / \mathrm{dl}, 6.36 \pm 1.36 \%, 116.7 \pm 31.9 \mathrm{mg} / \mathrm{dl}$, and $76.9 \pm 22.5 \mathrm{ml} / \mathrm{min} / 1.73 \mathrm{~m}^{2}$, respectively (Table 1).

Genotyping was carried out with genomic DNA isolated from human leukocytes by a commercial kit (QIAamp DNA Blood Mini Kit QIAGEN Inc., Japan). Angiotensinogen (AGT) M235T variant (rs699), [17] angiotensin II type I receptor (AT1) A1166C variant (rs5186) [18], and aldosterone synthase (CYP11B2) C-344T variant (rs1799998) [19] were assayed using the TaqMan method (Applied Biosystems, Foster city CA). Angiotensin converting enzyme (ACE) insertion/deletion (I/D) variant [20] was assayed by TaqMan method with special modification [21].

\section{Statistical analysis}

The sample size of the study was calculated by setting the difference to be detected between gene groups at least
Table 1 Baseline characteristics of subjects

\begin{tabular}{ll}
\hline Characteristics & \\
\hline Number & 782 \\
Diabetes mellitus [no. (\%)] & $282(36.1 \%)$ \\
Male gender [no. (\%)] & $365(46.7 \%)$ \\
Age (year) & $63.0 \pm 13.9$ \\
Body mass index ${ }^{\mathrm{a}}$ & $23.9 \pm 3.9$ \\
Blood glucose (mg/dl) & $119.7 \pm 42.7$ \\
Glycosylated hemoglobin (\%) & $6.36 \pm 1.36$ \\
Triglyceride (mg/dl) & $100.0(68.0-143.0)$ \\
Cholesterol (mg/dl) & \\
High-density lipoprotein & \\
Low-density lipoprotein $^{\mathrm{b}}$ & $53.0(44.0-63.0)$ \\
eGFR (ml/min/1.73 ${ }^{2}$ ) & $116.7 \pm 31.9$ \\
\hline
\end{tabular}

Plus-minus values are mean $\pm \mathrm{SD}$

$e G F R$ estimated glomerular filtration rate

a The body mass index is the weight in kilograms divided by square of the height in meters

b Values shown are medians (interquartile ranges)

$10 \%$ of DM prevalence. By using $\chi^{2}$ analysis with $5 \%$ of significance level and $80 \%$ of power, it was calculated the study required 728 subjects in total. All statistical analyses were conducted using the SPSS version 11.0J (SPSS Japan, Inc., Japan). The allele frequencies for each genotype were tested by contingency table analysis. $p<0.05$ was regarded as statistically significant. Data were presented as numbers, percentage, mean $\pm \mathrm{SD}$, or medians (interquartile ranges), as appropriate. The differences between two groups were analyzed by Student's $t$ test or Wilcoxon signed rank test as appropriate. Dichotomous characteristics were compared with use of the $\chi^{2}$ analysis for tests including Hardy-Weinberg equilibrium. Odds ratios for diabetes and $95 \%$ confidential intervals were calculated using multivariate logistic regression for each dichotomous characteristic to adjust potential confounding factors.

\section{Results}

Between non-diabetics and diabetics, we compared baseline characteristics of subjects (Table 2). Many items including age, gender, BMI, blood glucose, glycosylated hemoglobin, and lipids profiles showed significant difference between two groups.

The numbers of individuals with each genotype were as follows: DD, ID, and II genotypes of ACE D/I were 111, 337, and 334, respectively; MM, MT, and TT genotypes of AGT M235T were 27, 236, and 519, respectively; AA, AC, and CC genotypes of AT1 A1166C were 672, 104, and 6, respectively; $\mathrm{CC}$, TC, and TT genotypes of CYP11B2 
Table 2 Comparison of baseline characteristics of subjects between non-diabetics and diabetics

\begin{tabular}{|c|c|c|c|}
\hline Characteristics & $\mathrm{DM}(-)$ & $\mathrm{DM}(+)$ & $p$ value $^{\mathrm{a}}$ \\
\hline Number & 500 & 282 & \\
\hline Gender $[($ male $) \%]$ & 41.8 & 55.7 & $<0.001$ \\
\hline Age ( $\geq 65$ year) $(\%)$ & 45.2 & 55.0 & 0.005 \\
\hline $\begin{array}{l}\text { Body mass index } \\
(\geq 23)^{\mathrm{a}}(\%)\end{array}$ & 53.8 & 60.4 & 0.047 \\
\hline Blood glucose (mg/dl) & $101.0 \pm 13.1$ & $152.4 \pm 55.1$ & $<0.001$ \\
\hline $\begin{array}{l}\text { Glycosylated } \\
\text { hemoglobin }(\%)\end{array}$ & $5.52 \pm 0.41$ & $7.51 \pm 1.37$ & $<0.001$ \\
\hline Triglyceride $(\mathrm{mg} / \mathrm{dl})^{\mathrm{b}}$ & $\begin{array}{l}94.0 \\
\quad(65.0-135.5)\end{array}$ & $\begin{array}{l}106.5 \\
\quad(76.75-159.0)\end{array}$ & 0.001 \\
\hline \multicolumn{4}{|l|}{ Cholesterol (mg/dl) } \\
\hline $\begin{array}{l}\text { High-density } \\
\text { lipoprotein }^{\mathrm{b}}\end{array}$ & $\begin{array}{l}57.0 \\
\quad(47.0-65.0)\end{array}$ & $\begin{array}{l}47.0 \\
\quad(41.0-58.0)\end{array}$ & $<0.001$ \\
\hline $\begin{array}{l}\text { Low-density } \\
\text { lipoprotein }\end{array}$ & $117.0 \pm 31.7$ & $116.2 \pm 32.3$ & 0.749 \\
\hline $\begin{array}{l}\text { eGFR }(\mathrm{ml} / \mathrm{min} / \\
\left.1.73 \mathrm{~m}^{2}\right)\end{array}$ & $76.3 \pm 19.5$ & $77.8 \pm 27.0$ & 0.381 \\
\hline
\end{tabular}

Plus-minus values are mean $\pm \mathrm{SD}$

$e G F R$ estimated glomerular filtration rate

a The body mass index is the weight in kilograms divided by square of the height in meters

b Values shown are medians (interquartile ranges)

C-344T were 70,344 , and 368, respectively. The distributions were similar to those expected from HardyWeinberg equilibrium. The distribution of diabetes status and genotypes of each RAS gene is shown in Table 3 . Odds ratios for DM of each genotypes are as follows: About ACE (D/I) genotype, the risk of II to DD/DI was 1.186 [95\% confidence interval (CI) 0.884-1.592, $p=0.144]$. About AGT (M235T) genotype, the risk of TT to MM/MT was 1.157 (95\% CI 0.848-1.5680, $p=0.200$ ). About AT1 (A1166C) genotype, the risk of AA to AC/CC was 1.245 (95\% CI $0.810-1.916, p=0.186)$. About CYP11B2 (C-344T) genotype, the risk of CC/CT to TT was 1.359 (95\% CI $1.012-1.824, p=0.024)$. Thus, a significant association with DM was observed at aldosterone synthase variant with about 1.4 times risk.

Several confounding factors especially age effected on the results, finally a multivariate logistic regression was performed with 4 variables (Table 4). Considering that the dyslipidemia is attributed to metabolic disorder from diabetes, dyslipidemia was excluded from the final model of the analysis. Only age, gender, and CYP11B2 genotype were shown to be independent factors for association to diabetes. Thus, it was confirmed that a 1.4-fold increase in the odds for diabetes in subjects with $\mathrm{C}$ allele of CYP11B2 [Odds ratio $1.40(95 \%$ CI 1.04-1.90, $p=0.029)$ ].

\section{Discussion}

It is well known that diverse factors affect onset of type 2 DM including so-called environmental and genetic ones. First, male gender has been known to be risk for the condition from cohort studies [22]. Age and obesity are also well known to be important environmental factors for type 2 DM [23, 24]. Our study also clearly indicated these factors are surely risk of type $2 \mathrm{DM}$ in monovariate evaluations. Thus, we adjusted the confounding effects of these factors by multivariate logistic regression analysis. And it was well confirmed that the CYP11B2 variant is still independent risk of type $2 \mathrm{DM}$.

On general, for exploration of risk alleles for polygenic conditions, fundamentally two methods have been developed, candidate gene approach method and reverse genetics method including GWAS, one ultimate form of reverse genetics. The candidate gene approach is conducted to associations between genetic variations within genes of interest by known biological functions. On the contrary, GWAS scan the entire genome for common genetic variation without any biological foresight. Thus, GWAS is thought to be a strong tool for extract considerable part of causal genes unexpected from known pathophysiology;
Table 3 Distribution of genotypes of each gene and diabetes status

$N$ number, $A C E$ angiotensin converting enzyme, $A G T$ angiotensinogen, AT1 angiotensin II type I receptor, CYP11B2 aldosterone synthase, $D M$ diabetes mellitus, $95 \% C I$ $95 \%$ confidence interval

\begin{tabular}{|c|c|c|c|c|c|c|c|c|c|}
\hline & \multirow[t]{2}{*}{$\mathrm{N}$} & \multicolumn{2}{|c|}{$\mathrm{ACE}(\mathrm{D} / \mathrm{I})$} & \multicolumn{2}{|c|}{ AGT (M235T) } & \multicolumn{2}{|c|}{ AT1 (A1166C) } & \multicolumn{2}{|c|}{$\begin{array}{l}\text { CYP11B2 (C- } \\
344 \mathrm{~T})\end{array}$} \\
\hline & & DD/DI & II & $\mathrm{MM} / \mathrm{MT}$ & $\mathrm{TT}$ & AA & $\mathrm{AC} / \mathrm{CC}$ & $\mathrm{CC} / \mathrm{CT}$ & $\mathrm{TT}$ \\
\hline $\mathrm{DM}(-)$ & 500 & 294 & 206 & 174 & 326 & 425 & 75 & 251 & 249 \\
\hline $\mathrm{DM}(+)$ & 282 & 154 & 128 & 89 & 193 & 247 & 35 & 163 & 119 \\
\hline $\begin{array}{l}\text { OR }(95 \% \mathrm{CI}) \\
\text { (risk for } \mathrm{DM})\end{array}$ & & \multicolumn{2}{|c|}{$\begin{array}{l}1.186 \\
(0.884-1.592)\end{array}$} & \multicolumn{2}{|c|}{$\begin{array}{l}1.157 \\
(0.848-1.5680)\end{array}$} & \multicolumn{2}{|c|}{$\begin{array}{l}1.245 \\
(0.810-1.916)\end{array}$} & \multicolumn{2}{|c|}{$\begin{array}{l}1.359 \\
(1.012-1.824)\end{array}$} \\
\hline \multicolumn{2}{|l|}{$\chi^{2}$} & \multicolumn{2}{|l|}{1.294} & \multicolumn{2}{|l|}{0.848} & \multicolumn{2}{|c|}{1.000} & \multicolumn{2}{|l|}{4.182} \\
\hline$p$ value & & \multicolumn{2}{|l|}{0.144} & \multicolumn{2}{|l|}{0.200} & \multicolumn{2}{|c|}{0.186} & \multicolumn{2}{|l|}{0.024} \\
\hline
\end{tabular}


Table 4 Multivariate logistic regression analysis for diabetes

\begin{tabular}{|c|c|c|c|c|c|}
\hline Variables & $\beta$ & SE & $\begin{array}{l}\text { Wald's } \\
\chi^{2}\end{array}$ & $\begin{array}{l}\text { Odds Ratio } \\
(95 \% \text { CI })\end{array}$ & $p$ value \\
\hline $\begin{array}{l}\text { Gender } \\
\quad \text { (male, } \\
41.8 \% \text { ) }\end{array}$ & 0.625 & 0.154 & 16.40 & $1.87(1.38-2.53)$ & $<0.001$ \\
\hline $\begin{array}{l}\text { Age } \\
\qquad(\geq 65 \text { year } \\
48.7 \%)\end{array}$ & 0.455 & 0.155 & 8.64 & $1.58(1.16-2.14)$ & 0.003 \\
\hline $\begin{array}{r}C Y P 11 B 2 \\
(\mathrm{CC} / \mathrm{CT}, \\
52.9 \%)\end{array}$ & 0.337 & 0.154 & 4.77 & $1.40(1.04-1.90)$ & 0.029 \\
\hline $\begin{array}{l}\text { Body mass } \\
\text { index }(\geq 23 \\
56.2 \%)\end{array}$ & 0.202 & 0.161 & 1.57 & $1.22(0.89-1.68)$ & 0.211 \\
\hline
\end{tabular}

Multivariate logistic regression was performed to adjust to potential confounding factor for diabetes. All factors in this table were included in the final model

$95 \%$ CI $95 \%$ confidence interval, CYP11B2 aldosterone synthase

a The body mass index is the weight in kilograms divided by square of the height in meters

however, the obtained results do not always explain most part for type 2 DM [1-3]. This limit of GWAS is thought to be attributed to the so-called genome-wide strict significance level to avoid problems of multiple comparisons $\left(p<5 \times 10^{-8}\right)$. Thus, candidate gene approach is thought to be still useful to find responsible genes. Recent reports for the blockade of the RAS showed reduction in new onset of type $2 \mathrm{DM}$ as sub-analysis, implying that the system might be involved in the onset of DM [11-13]. Plausible explanation has been made mainly by reduction in oxidative stress via the blockade of the system. Thus, the study substantiated the hypothesis that genetic variants of the RAS have significant association with prevalence of DM. So far, the association between the RAS genetic variants and the prevalence of type $2 \mathrm{DM}$ has been examined in a small number of studies. Yang reported that interactions among RAS-related genes combination including ACE D/I polymorphism were associated with type 2 diabetes in a Chinese population [25]. A meta-analysis by Zhou reported that ACE I/D polymorphism is not associated with type 2 DM in a Chinese population [26]. As to CYP11B2, no report was made about the association with DM prevalence until now to our knowledge.

The $\mathrm{C}-344 \mathrm{~T}$ is a promoter region polymorphism and thought to be a putative binding site for the steroidogenic transcription factor SF-1 [19] and might be associated with hypertension and salt sensitivity with inconsistency [2732]. About the association between C-344T genetic variant and plasma aldosterone concentration is also controversial. Tamaki reported that the TC/CC genotypes were significantly associated with higher plasma aldosterone concentration/plasma renin activity [29]. However, majority of studies about plasma aldosterone concentration reported that the $-344 \mathrm{~T}$ allele was associated with higher plasma aldosterone levels [28, 31, 32]. In this context, it is thought to be plausible that the $-344 \mathrm{~T}$ allele might rather indicate a high prevalence of DM as presumed hypo-potassemic tendency by high plasma aldosterone. However, the results showed that the $-344 \mathrm{C}$ allele tends to high DM prevalence. One strained possible explanation might be as follows: against the high plasma aldosterone tendency, plasma renin and angiotensin II might be reduced as a consequence of negative feedback and these reductions might lead to some anti-diabetic state. Thus, the result of the study should be difficult to explain clearly.

Several limitations of this study should be noted. We have calculated the sample size in consideration of type I error of 5 and $80 \%$ of power; however, the sample number is still relatively small. Especially, the power calculation was not enough for the AT1 because of a small number for minor alleles 110 of 782 subjects. We evaluated 4 independent genetic variants. Accordingly, a correction for multiple testing might be needed. On this point, $p$ value threshold 0.05 for significance might be relatively large. And one another limitation was that only one genetic variant for each gene was assayed.

In conclusion, this study provides a support that a genetic variant of CYP11B2 gene, C-344T is associated to prevalence of type $2 \mathrm{DM}$, in other words, the variant might be an independent predictor for the type 2 diabetes. Thus, a new possibility for personalized medicine by genetic variants of the renin-angiotensin system has been shown in the area of metabolic conditions. Further studies are necessary including other SNPs in each gene.

Acknowledgments This work was supported by grant-in-aids 08770879, 09770843, 14571020, 22590909 and 25461245 from the Ministry of Education, Science and Culture of Japan and a grant from National Research Foundation/Japan Science and Technology Agency (NRF/JST) (Project Number: J110000349) and Strategic international research cooperative program (SICP). We are grateful to the study investigators of the Genomic Disease Outcome Consortium (G-DOC), which was organized as the Kanazawa Renal Disease Study Group on 1995 for presenting a part of the subjects of this study. We are also grateful to Miss Yoko Hayashida (employer/ institution/affiliation: Third Department of Internal Medicine, University of Fukui Faculty of Medical Sciences, Fukui, Japan) for technical and secretarial assistance.

\section{Conflict of interest None.}

Human and Animal Rights All procedures followed were in accordance with the ethical standards of the ethics committee of Fukui University (n. 13.1/14.2) with the Helsinki Declaration of 1975, as revised in 2008 (5).

Informed Consent Informed consent was obtained from all patients for being included in the study. 
Open Access This article is distributed under the terms of the Creative Commons Attribution License which permits any use, distribution, and reproduction in any medium, provided the original author(s) and the source are credited.

\section{References}

1. Sladek R, Rocheleau G, Rung J et al (2007) A genome-wide association study identifies novel risk loci for type 2 diabetes. Nature 445:881-885

2. Zeggini E, Scott LJ, Saxena R et al (2008) Meta-analysis of genome-wide association data and large-scale replication identifies additional susceptibility loci for type 2 diabetes. Nat Genet 40:638-645

3. Yamauchi T, Hara K, Maeda S et al (2010) A genome-wide association study in the Japanese population identifies susceptibility loci for type 2 diabetes at UBE2E2 and C2CD4A-C2CD4B. Nat Genet 42:864-868

4. Corvol P, Soubrier F, Jeunemaitre X (1997) Molecular genetics of the renin-angiotensin-aldosterone system in human hypertension. Pathol Biol (Paris) 45:229-239

5. Dzau V (2005) The cardiovascular continuum and renin-angiotensin-aldosterone system blockade. J Hypertens Suppl 23:S9-17

6. Wakahara S, Konoshita T, Mizuno S et al (2007) Synergistic expression of angiotensin-converting enzyme (ACE) and ACE2 in human renal tissue and confounding effects of hypertension on the ACE to ACE2 ratio. Endocrinology 148:2453-2457

7. Konoshita T, Wakahara S, Mizuno S et al (2006) Tissue gene expression of renin-angiotensin system in human type 2 diabetic nephropathy. Diabetes Care 29:848-852

8. Brenner BM, Cooper ME, de Zeeuw D et al (2001) Effects of losartan on renal and cardiovascular outcomes in patients with type 2 diabetes and nephropathy. N Engl J Med 345:861-869

9. Lewis EJ, Hunsicker LG, Clarke WR et al (2001) Renoprotective effect of the angiotensin-receptor antagonist irbesartan in patients with nephropathy due to type 2 diabetes. $\mathrm{N}$ Engl J Med 345:851-860

10. Parving HH, Lehnert H, Brochner-Mortensen J et al (2001) The effect of irbesartan on the development of diabetic nephropathy in patients with type 2 diabetes. N Engl J Med 345:870-878

11. (2002) Major outcomes in high-risk hypertensive patients randomized to angiotensin-converting enzyme inhibitor or calcium channel blocker vs diuretic: the antihypertensive and lipid-lowering treatment to prevent heart attack trial (ALLHAT). JAMA 288: 2981-2997

12. Julius S, Kjeldsen SE, Weber M et al (2004) Outcomes in hypertensive patients at high cardiovascular risk treated with regimens based on valsartan or amlodipine: the VALUE randomised trial. Lancet 363:2022-2031

13. Ogihara T, Nakao K, Fukui T et al (2008) Effects of candesartan compared with amlodipine in hypertensive patients with high cardiovascular risks: candesartan antihypertensive survival evaluation in Japan trial. Hypertension 51:393-398

14. Cambien F, Poirier O, Lecerf L et al (1992) Deletion polymorphism in the gene for angiotensin-converting enzyme is a potent risk factor for myocardial infarction. Nature 359:641-644

15. Konoshita T, Miyagi K, Onoe T et al (2001) Effect of ACE gene polymorphism on age at renal death in polycystic kidney disease in Japan. Am J Kidney Dis 37:113-118
16. Konoshita T, Kato N, Fuchs S et al (2009) Genetic variant of the renin-angiotensin system and diabetes influences blood pressure response to angiotensin receptor blockers. Diabetes Care 32:1485-1490

17. Jeunemaitre X, Soubrier F, Kotelevtsev YV et al (1992) Molecular basis of human hypertension: role of angiotensinogen. Cell 71:169-180

18. Bonnardeaux A, Davies E, Jeunemaitre X et al (1994) Angiotensin II type 1 receptor gene polymorphisms in human essential hypertension. Hypertension 24:63-69

19. White PC, Slutsker L (1995) Haplotype analysis of CYP11B2. Endocrine Res 21:437-442

20. Rigat B, Hubert C, Corvol P, Soubrier F (1992) PCR detection of the insertion/deletion polymorphism of the human angiotensin converting enzyme gene (DCP1) (dipeptidyl carboxypeptidase 1). Nucleic Acids Res 20:1433

21. Koch W, Latz W, Eichinger M, Ganser C, Schomig A, Kastrati A (2005) Genotyping of the angiotensin I-converting enzyme gene insertion/deletion polymorphism by the TaqMan method. Clin Chem 51:1547-1549

22. Leibson CL, O'Brien PC, Atkinson E, Palumbo PJ, Melton LJ 3rd (1997) Relative contributions of incidence and survival to increasing prevalence of adult-onset diabetes mellitus: a population-based study. Am J Epidemiol 146:12-22

23. Harris MI, Flegal KM, Cowie CC et al (1998) Prevalence of diabetes, impaired fasting glucose, and impaired glucose tolerance in U.S. adults. The Third National Health and Nutrition Examination Survey, 1988-1994. Diabetes Care 21:518-524

24. Colditz GA, Willett WC, Rotnitzky A, Manson JE (1995) Weight gain as a risk factor for clinical diabetes mellitus in women. Ann Intern Med 122:481-486

25. Yang JK, Zhou JB, Xin Z et al (2010) Interactions among related genes of renin-angiotensin system associated with type 2 diabetes. Diabetes Care 33:2271-2273

26. Zhou D, Ruiter R, Zhang J et al (2012) Angiotensin-converting enzyme I/D polymorphism is not associated with type 2 diabetes in a Chinese population. JRAAS 13:372-378

27. Brand E, Chatelain N, Mulatero P et al (1998) Structural analysis and evaluation of the aldosterone synthase gene in hypertension. Hypertension 32:198-204

28. Paillard F, Chansel D, Brand E et al (1999) Genotype-phenotype relationships for the renin-angiotensin-aldosterone system in a normal population. Hypertension 34:423-429

29. Tamaki S, Iwai N, Tsujita Y, Kinoshita M (1999) Genetic polymorphism of CYP11B2 gene and hypertension in Japanese. Hypertension 33:266-270

30. Tsujita Y, Iwai N, Katsuya T et al (2001) Lack of association between genetic polymorphism of CYP11B2 and hypertension in Japanese: the Suita Study. Hypertens Res 24:105-109

31. Barbato A, Russo P, Siani A et al (2004) Aldosterone synthase gene (CYP11B2) C-344T polymorphism, plasma aldosterone, renin activity and blood pressure in a multi-ethnic population. J Hypertens 22:1895-1901

32. Iwai N, Kajimoto K, Tomoike H, Takashima N (2007) Polymorphism of CYP11B2 determines salt sensitivity in Japanese. Hypertension 49:825-831 